\title{
Cloud Based Career Guidance System
}

\author{
Harsh Mishra ${ }^{1}$, Jatin Makad ${ }^{2}$, Nikhil Pathak ${ }^{3}$, Dr.Gaurav Soni ${ }^{4}$ \\ ${ }^{1}$ Lovely Professional University, Kanpur, Uttar Pradesh, India \\ ${ }^{2}$ Lovely Professional University, Jodhpur, Rajasthan, India \\ ${ }^{3}$ Lovely Professional University, Haridwar, Uttarakhand, India \\ ${ }^{4}$ Lovely Professional University, Phagwara, Punjab, India
}

\section{Article Info \\ Volume 7, Issue 2 \\ Page Number: 640-649}

Publication Issue :

March-April-2021

\section{Article History}

Accepted : 25 April 2021

Published : 30 April 2021

\section{ABSTRACT}

Cloud based mostly Career guidance system is extremely necessary to our academic System. We've an existing internet based Career guidance system obtainable on internet with varied issues : System not obtainable all the time, Not giving free courses to the scholars, no courses for studies, not specializing in new trends. We've been ready to style a web Career guidance device targeting students who have passed their faculty and area unit trying to find ensuing begin to their career and that we have conjointly targeted on the scholars who have money issues and can't afford courses on the platform . Internet based mostly Career guidance device was designed and enforced victimization knowledge collected from measuring totally different career guidance device obtainable on web. The subsequent scripting languages were employed: PHP, MySQL, HTML, Java Script, Bootstrap and CSS. The system was enforced and tested with fifty students and seventy six of them found the career system terribly helpful.

Keywords : Web, Career, Guidance, information system, Educational System, Counselors

\section{INTRODUCTION}

Guidance could be a term generally used broadly speaking to visit advising or serving to a personal with any quite educational, business or personal drawback. It can also be observed as a service provided by the particular faculty to assist young persons in creating clever call and changes thus on develop their potentials as a personal and a contributive member of the society. [2] Steerage activities square measure sometimes associated with instructional professionals called counselors likewise because the involvement of fogeys, relatives, teachers, directors, alternative instructional specialists, non secular leaders etc. The that means is thus broad that it doesn't affect education alone however also aspects of life that affects a personal, therefore we can say that steerage is additionally a method of serving to a person to comprehend and 
grow his/her business, educational, and psychological potentials and additionally achieving AN the simplest level of individual happiness and social group quality. Career guidance consists of services that facilitate individuals with success manage their career development. though this facet of human development happens on its own as we have a tendency to mature, everybody will like help navigating through this method.(Dawn, 2012). Career steering may be a set of intervention ways designed to ease the career development of the individual. Career steering may be a broad term, which has the event of job search, on interview skills, placement into a selected vocation, and follows up the location to make sure effectiveness. In career steering, direction is employed together of the interventional ways.

The British Association of Counselors (BAC) now the $\mathrm{BACP}$, were the very first professional association that adopted a definition of International Journal of Scientific Research in Science, Engineering and Technology (ijsrset.com) 230 professional counseling (Dawn, 2012), in 1986 they published this definition:

"Counseling is the skilled and principled use of relationship to facilitate self- knowledge, emotional acceptance and growth and the optimal development of personal resources. The overall aim is to provide an opportunity to work towards living more satisfyingly and resourcefully. Counseling relationships will vary according to need but may be concerned with developmental issues, addressing and resolving specific problems, making decisions, coping with crisis, developing personal insights and knowledge, working through feelings of inner conflict or improving relationships with others." (BASP, 1986) "Why will we would like an online primarily based career system" some might raise. it's become fully necessary because: i. The internet has become an area wherever students(youths) visit typically to interact(social network), shop(online shopping), be entertained(online video, music and radio services) etc. its solely correct that the net is additionally used for one thing as productive and as necessary as interacting with an system that helps them selected the simplest career doable for them.

ii. If properly designed and enforced, an internet career steering are often more practical and accessible than a true life counselor as a result of a student will get help any time.

iii. It are often wont to complement reality counselors; it will function a tool employed by them. Before the late nineteenth century, there was much very little or nothing living within the kind of career steering for persons considering obtaining employment. once it all started, career steering was noted as line of work steering. Work prospects started from near communal associates like family, friends and conjointly the church. The start of the 20thcentury saw an increase in immigration, innings is a rise within the would like for aa lot of structured means that to help folks in obtaining jobs.

Though the classes of professions have improved considerably within the previous century, a number of the fundamentals of career steering endure.

The principal themes still is that the development of an awareness of individual skills, ability and interests, conjointly being educated concerning career openings and demands. Conversely, career steering within the gift day is viewed as never-ending method. in contrast to before age isn't any longer a actuation, this has caused a rise within the stress on the self at work and work-life balance. 
In this paper section 2 explains the statement of the problem, Aim and objective in section 3, Significant of study in section 4, Analysis of the existing system in section 5, Possible solutions in section 6, Justification of the new system on section 7, Methodology in section 8, Proposed Design System in section 9 and Results in section 10 and Conclusion.

\section{Literature Survey}

We have used html, css and bootstrap for the frontend of our website. These technologies are mostly used for designing a good frontend for our projects and we have also used bootstrap component to make it more responsive. For the Test procedure we have designed the test part using JavaScript by which a student can give the test and will get a proper score and career choice to go for. Php and sql for the backend of our site.

1. The website of the proposed[10] career and educational guidance system is entirely cloudbased. The system will be divided into various categories like login \& signup section and it consists of different courses and free courses section and a test module

2. The main modules that the project includes is the courses section[14] where a user can explore every course on the site and other is the free courses section where a user can explore free courses and a test section where a user can give a test and check his performance.

3. This is a cloud based[15] career guidance sytem which will be installed on cloud and will be accessible.

\section{A. Statement of the matter}

This paper intends to unravel the subsequent problems:
1. Out of stock human counselors in some colleges. This has leading to several students creating wrong career decisions and so regretting for the remainder of their lives.

2. Wherever the advisors area unit offered, there area unit largely not enough to cater for all the scholars.

3. Real world counselors area unit solely offered to students at operating hours of the day, however an internet career counselor is accessible at any time and simply a click away.

4. the most of the Online Career Guidance system does not offer free courses or scholarship to the students in need.

\section{B. Analysis Of The Existing System}

The analysis of the existing system is divided into two parts:

i. Analysis of the Manual System.

[3] In analyzing the area of career guidance and message from the overall read, we are going to\} see that or deduce that its goal is essentially to help students in developing the individual growth of that there are sure procedures that the steerage counselor uses throughout the course of his work, such procedures are:

Test: these are being developed to judge interest, talents and temperament traits, such tests are:

a) Intelligence tests that square measure given to live intellectual ability. The results of intelligence tests are termed I.Q. (IQ).

b) Action tests that square measure given to check the extent students have reached in verbal and mathematical skills yet as in specific areas like social studies, sciences and foreign languages.

c) Power takes a look at, these square measure tests designed to predict a student's ability during a explicit field.

d) Temperament tests, they will reveal a student's feeling, problem, attitudes, likes and dislikes during 
which conjointly determines what space of labor a student can get pleasure from the foremost.

e) Interest inventories, that facilitate students suppose clearly concerning career preferences during which on the idea of the results of those inventories, counselors could counsel careers the student had never thought-about before.

ii. Group Guidance: This includes those steerage activities which may be carried on economically and effectively with cluster of pupils. The cluster ways square measure used primarily to convey data as in orientation to a brand new college, in occupation categories, or in career conferences.

iii. Individual Interview/Counseling: By suggests that of non-public interviews the counselor helps the scholars with several of the everyday issues of growing up. It involves intimate temperament relationship between a pupil and also the counselor to that each of them discuss having Associate in Nursing objective angle yet as careful plans for the pupil so as to assist him build choices.

\section{Limitations of the Existing Manual System}

[7] The existing career guidance system is limited in the following ways:

I. The existing career guidance does not provide proper assistance to the students.

II. The career guidance system available on web does not provide courses related to new technologies.

III. These guidance systems does not provide free courses for the students in need.

IV. Some counsellors square measure not committed or diligent and might generally be unapproachable.

V. Counsellors will solely attend to students throughout operating hours of the day.

VI. The problem of generation gap: the overall plan among students is that the steerage and counsellor may be a middle aged man or lady United Nations agency is gave the impression to be old school therefore will solely provide suggestions or solutions in like manner.

VII. Counsellors square measure humans with their own emotions, personal responsibilities and pressures, therefore, the tendency of emotional eruption and absence from the workplace once required is inevitable. This discourages students from approaching them.

The quality and unknowingness of the steering and direction department in our secondary faculties makes the system beneath used, thereby creating it inefficient. Some students might realize the direction season a torture and boring so they avoid it. Lack of standardized and regionally custom-made career quiz or form

[5] Analysis of existing Online Career Guidance System

At the appearance of the twenty first century, the web has brought so many possibilities. Career steerage isn't associate exception; below square measure some existing on-line career steerage websites and their limitations.

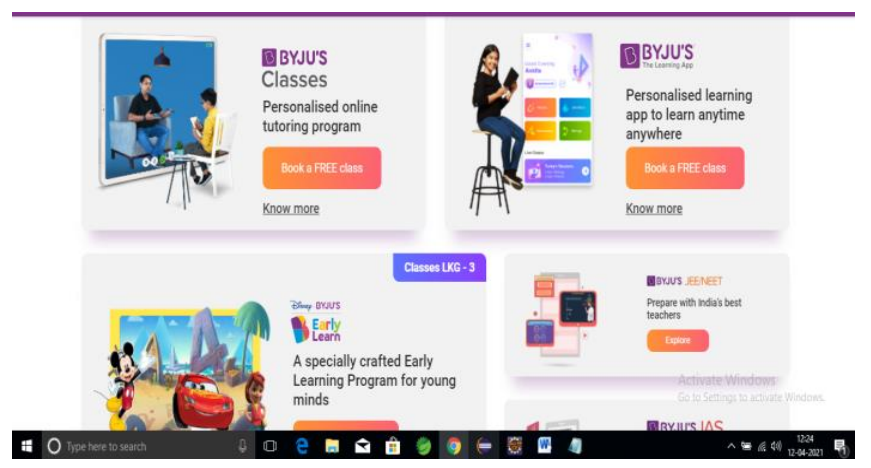

Figure 1 : A Paid Career Guide Website

Figure 1 on top of shows the web site with the url: www.byjus.com that demands that people who wish to use the career steering service should pay a fairly great amount of cash. There by creating it not accessible to people who aren't financially stable. No provision without free trial in the least. Associate 
Nursing objective of this analysis is to deploy a free career guidance system.

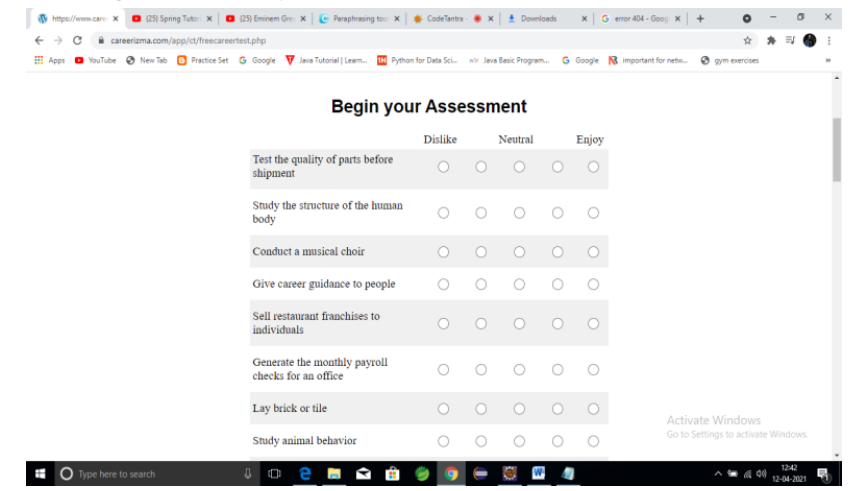

Figure 2. An Online Career Test Site With A

Difficulty To Understand Interface

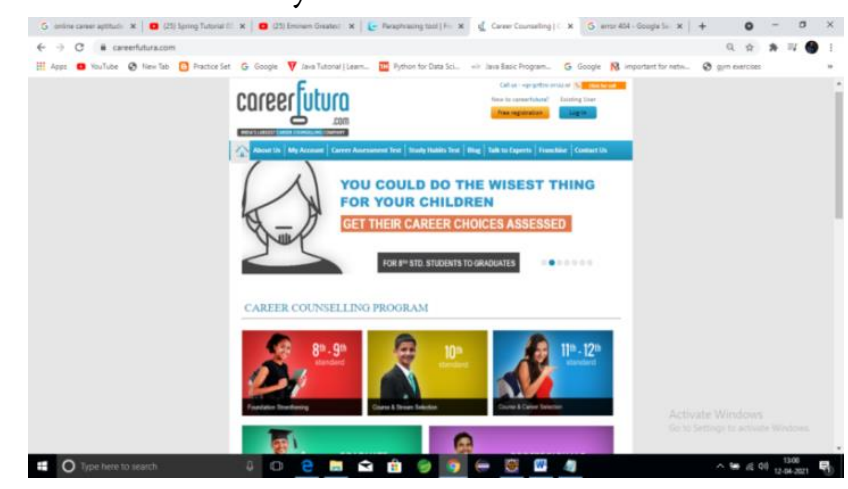

Figure 3- an Existing Online Career Guidance System

\section{Problem of The Existing Online System}

One of the foremost vital selections juvenile needs to build in life needs to do with a future career. [8] The selection of Associate in nursing career is seen because the second most significant call, next to the selection of a mate in wedding. the selection of Associate in Nursing career becomes vital as a result of it may verify the overlook of our success in life, our cluster of friends, business associates, recreational activities, opportunities, wage standing and general life vogue appeared to be determined or influenced by our career. the selection of a career has become a lot of complicated during this trendy time for the subsequent reasons:

i. India is a developing nation going through severe economic and financial problem resulting to unemployment in various categories of occupation. ii. The development in science and technology has diode to new careers of that the general public aren't aware.

iii. Many people lack ability to assess themselves for a practical selection of career.

iv. Information regarding varied occupations doesn't without delay get to those that ar considering the selection of career.

v. Absence of job satisfaction is an additional issue that has thrown many of us out of job.

vi. Parents, generally out of cognitive content force careers on their youngsters that become a retardant or is a brief happening for the kids.

vii. The contemporaries includes a mess of influence on youth career alternative. Several youth opt for occupation just because their friends have chosen such and that they don't wish to try to to something totally different from their friends.

viii. Several youth set high line of work aspirations for themselves while not possessing the required personal qualities to pursue such associate in nursing occupation.

ix. Inability of some youth to stay their career alternative versatile has junction rectifier to delays in obtaining admission and frustrations in meeting the necessities for the career of their alternative.

\section{Possible Solution}

The web system being designed during this paper to unravel same issues falls roughly underneath professional system.

i. Expert System - [1] An skilled system is associate interactive laptop based mostly call tool that uses each facts and heuristics in resolution tough higher cognitive process issues, supported data non inheritable from associate skilled.

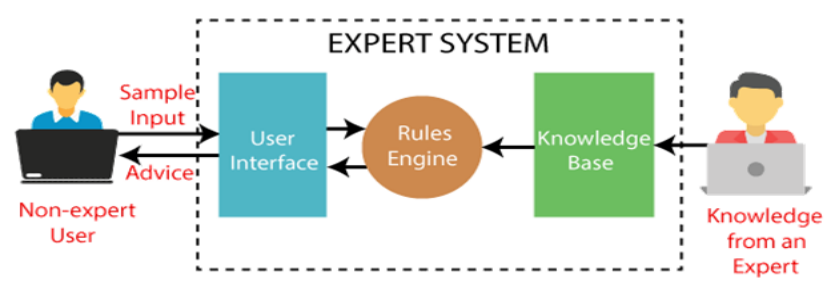


Figure 4. Components of Expert System

The Fig 4. Higher than shows a diagrammatical illustration of AN knowledgeable system, considering the analysis in sight, the scholars visiting the positioning in sight of obtaining career steerage are the user, I, the developer is each the data engineer and system engineer. The web site interface is the program.

\section{ii. Justification Of the New System}

The illation engine is that the $\mathrm{PHO}$ driven perform that works on the input of the user through the answers to the quiz taken, the knowledge domain and dealing storage ar each hold on within the info. In lightweight of the restrictions expressed higher than, it's expedient that a web career guidance device be created accessible for the Nigerian students. Here area unit a number of the inherent advantages:

o An internet primarily based career guidance device guarantees to be accessible and accessible by students at any time, any day and at their convenience (just a click away).

o This data system will function a complimentary tool for world counselors.

o The system intends to be tailored for University and Indian students.

\section{METHODOLOGY}

Investigations:

In 2014, a study was done to gauge however well professionals ${ }^{\text {ee }}$ square measure consummated or placid with the sort of career they're presently into, 314 professionals were interviewed. Those interviewed were over 35years older and from sixteen totally different professions around Benin town. The results square measure portrayed.

To design and implement a fully functional career guidance system the following approaches will be used. Understand absolutely what the analysis is concerning and what's needed of the planned system , outline the scope of the research.

Study the prevailing manual system associate degree draft out some way of computerizing an improved manual system.

Coming up with the net interface victimization hypertext mark-up language and CSS. Making a info for the analysis victimization WAMP. Linking the page with the info Bottom-Top methodology was employed in coming up with this analysis

\section{Data Collection}

The data utilized in formulating the career quiz for this analysis was obtained by interviewing career counsellors and adaptation of career questionnaires.

[10] At the course of testing this method twenty students truly registered on the online website, providing the subsequent information: forename, Last Name, Email address, sign, State of origin, Date of Birth and academic standing.

\section{THE PROPOSED DESIGN SYSTEM}

The development of career steerage and direction system lies on one in all the roots of professional system that is additionally one in all the most important roots in professional systems referred to as cognitive science i.e. the realm of human IP.

The study of psychological feature is extremely vital because of the actual fact that the human professional needs to be accessible for the information engineer to encipher his information into the programs thus on create the pc emulate the human. Within the case of this explicit analysis the information was non inheritable from the human specialists (career counsellors) by the suggests that of interview with them. 


\section{INPUT DESIGN [15]}

The input of this technique from the user purpose of read is essentially his actions on the pages of the positioning tha

conjure the system, these pages are going to be enforced by coding them with mark-up language (Hyper Text Mark-up Language) and also the page layout vogue\} through with CSS (cascade style sheet) \& BOOTSTRAP. The user can act with the system by clicking on menus associate degree hyperlinks yet as choosing the answers on the quiz page, the quiz answers are going to be enforced mistreatment radio buttons whereby only 1 possibility out of the four (4) are often picked.

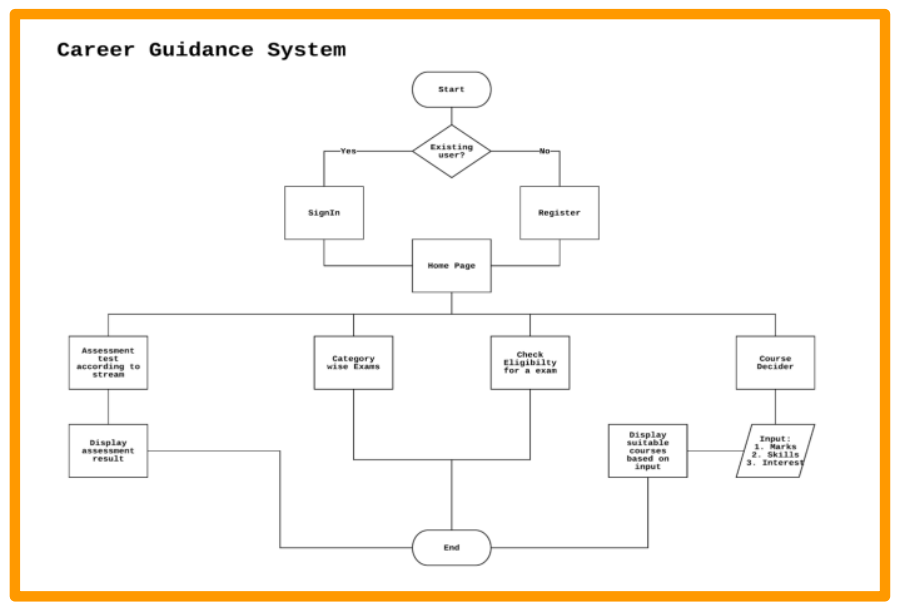

STORAGE DESIGN

The planned system can have a completely dynamic and practical information. The information are going to be created exploitation WAMP and queried exploitation SQL. the subsequent knowledge regarding the scholar are going to be collected and hold on within the database:

First Name (Input type $=$ Text)

Last Name (Input type $=$ Text

Email address (Input type $=$ Text)

Password (Input type $=$ Password)

State of origin (Input type= Option)

Phone Number (Input type $=$ Text)

Date of Birth (Input type= Option)
Gender (Input type $=$ Radio)

Educational Status (Input type= Checkbox)

[12] The quiz queries additionally are going to be hold on within the information and afterwards retrieved exploitation PHP and SQL commands, the results of the quiz will be hold on within the information and might be retrieved any time the scholar revisits the location. A student will take the quiz many times and also the results of every quiz are going to be hold on for future use or reference

\section{RESULTS AND DISCUSSION}

The output of the Career Guidance System is typically the courses and the path that is chosen by the student for their career. [11]

\section{LOGIN AND SIGN UP PAGE}
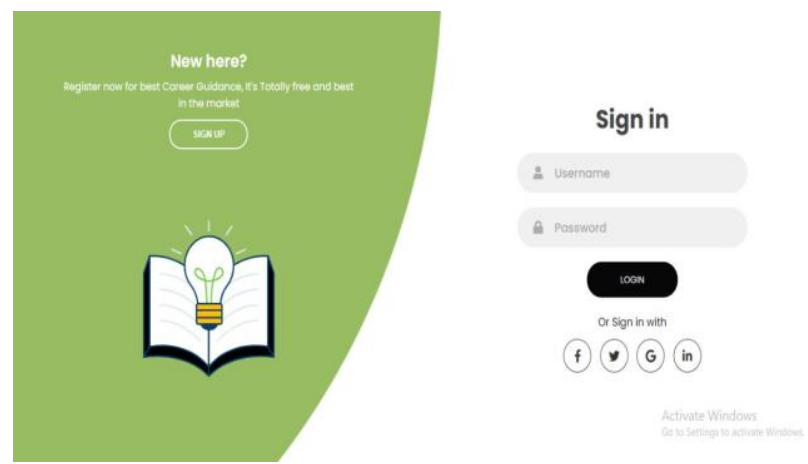

Figure 5. Login Page

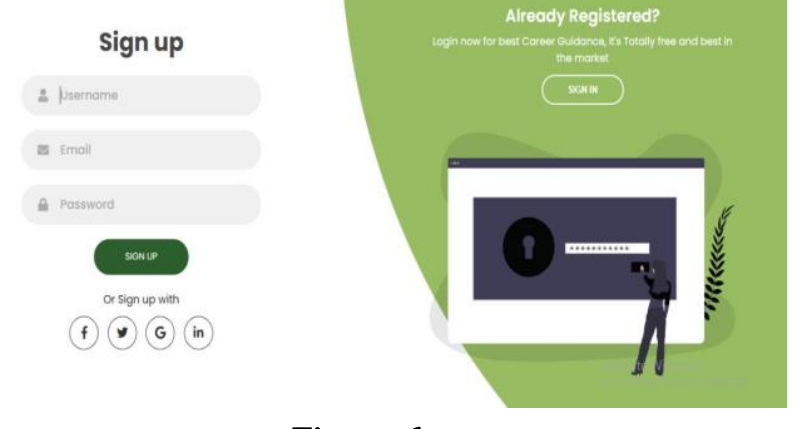

Figure 6

This is the login and signup section where a user can login and explore the website and a new user can register him/herself. 


\section{THE LANDING PAGE}

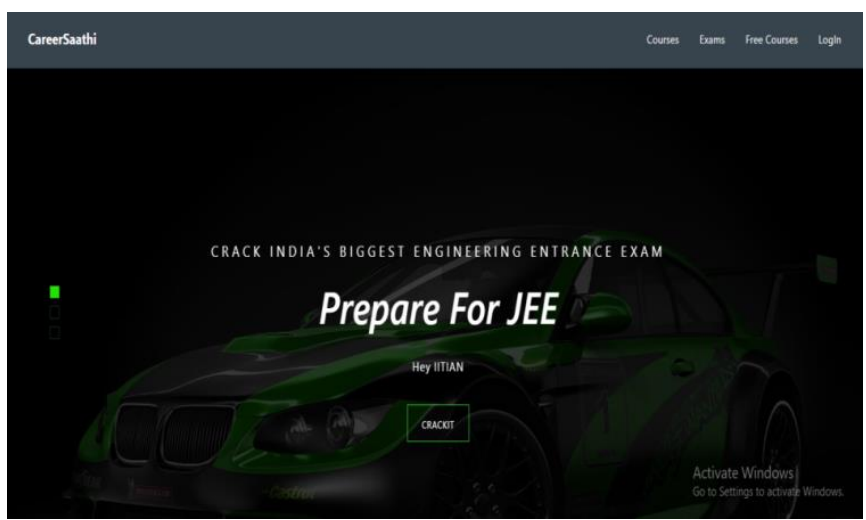

Figure 7. The landing Page

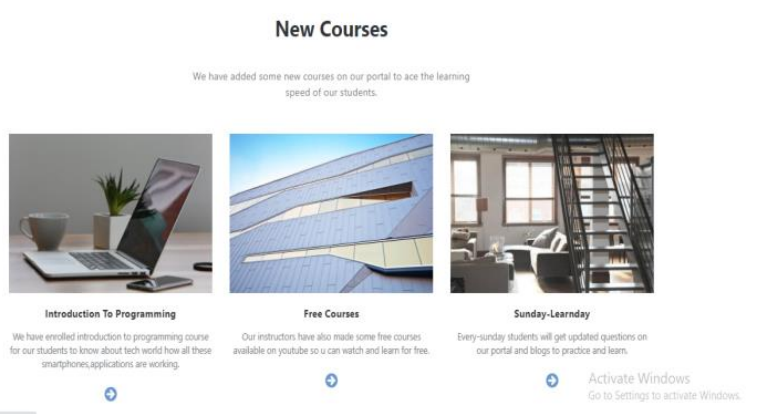

Figure 8. Courses Section

The figure 3,4 comprises of whole Home page which consist of a slider, cards, nav-bar, footer when the user will visit the website this will be the first page where user will land here user will get options to sign up , login, view courses and many more.

Privacy Policy And Front Page

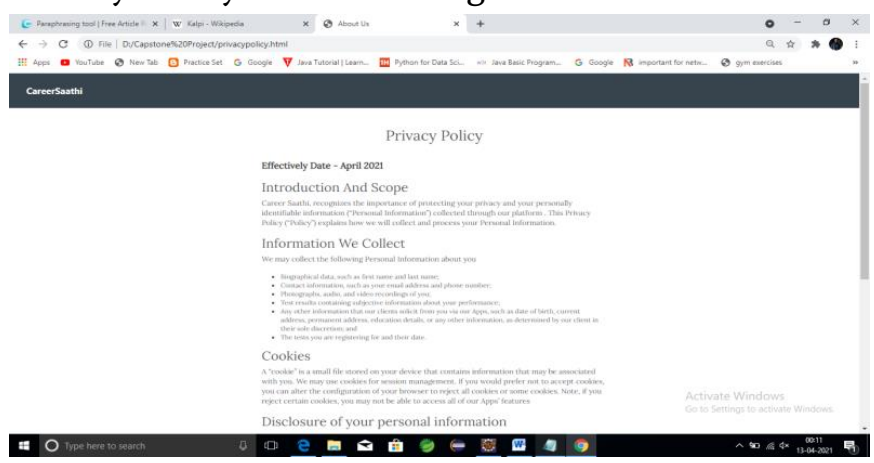

Figure 9. Privacy Policy page

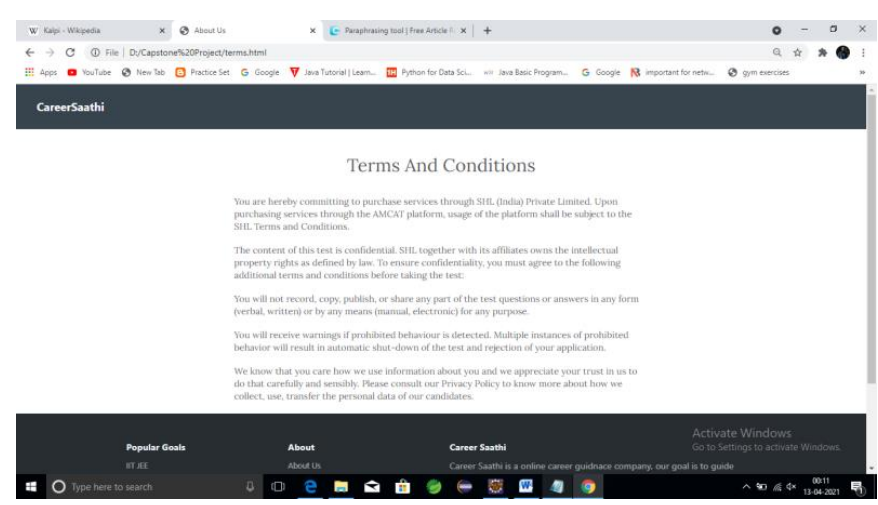

Figure 10. Terms And Condition

Fig 6 and 7 is the privacy policy and terms and condition page the user can visit this page to know the career saathi policies before registering him/herself in the portal.

Courses Section

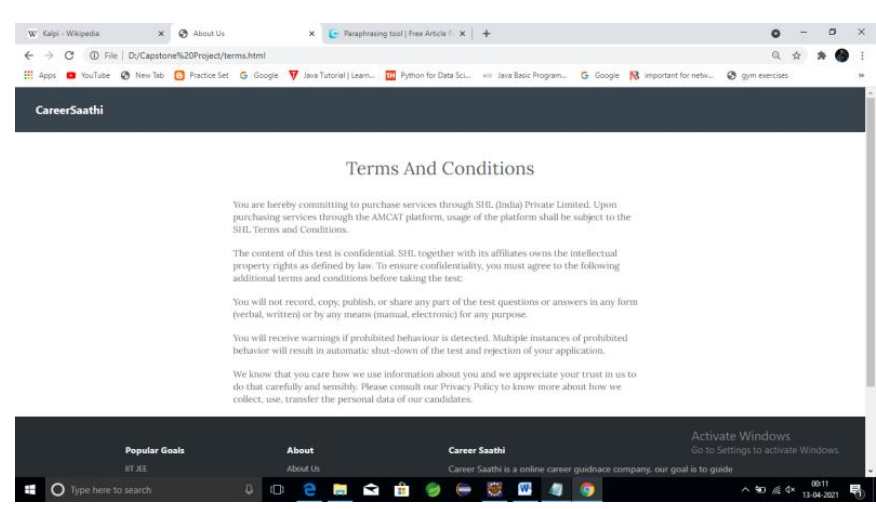

Figure 11

This is the courses section where the student will found out different courses related to programming and other skills in it and other fields where the students can learn and earn new skills.

System Testing And Integration [13] \& [14]

The method of implementation for this analysis is Parallel implementation. This suggests the system is to be utilized in conjunction with the already existing manual counselling program. The appliance seeks to enhance the prevailing manual system and might even be used as a tool for counsellors. It's supposed to be used as a standalone system for college students 
and colleges UN agency UN agency have access to an individual's career guide or counsellor.

Since the system may be a net primarily based system it are often accessed by the suggests that of any device that contains a valid application program and a useful net affiliation from anyplace within the globe.

The system are often integrated into middle school web site or students inspired to go to the online page by their academics, oldsters or career counsellor in class.

\section{Discussions}

During the course of the analysis, the manual career system was critically studied and a few shortcomings were seen, places of improvement were discovered and an area that a web system will match.

[16] We tend to saw that a web career system can prove extremely useful in our gift day, nearly everything is finished on-line currently, and also the cohort of these that this analysis scope covers spends an honest variety of their time on the net doing less productive things, it's imperative and necessary that they be inspired to interact in productive activities like determinative the simplest career attainable for them.

\section{Future Work}

Future Work - Our Project Career guidance system is based on giving students their career path to help them choosing their career. In future to make our website better we can go for live classes and tests and tie up with some companies for industry trainings to help students with easy choice of their career so that they can upgrade their skills too.

\section{Recommendation}

It is extremely suggested that this analysis be improved upon and enforced as this can be terribly helpful to the society at giant. A society full of voters World Health Organization square measure consummated with what they are doing for a living will go an extended method in rising general health and scale back violence rate.

A live and purposeful chat system may also be enclosed to assist students World Health Organization aren't clear with the advice given by the system.

\section{CONCLUSION}

In this analysis work we've got been able to explore the issues encountered by the present manual system, to style an internet based mostly\} career system which will improve upon the present manual/ human career guide and to implement an internet based application which will facilitate young ones get an honest understanding of themselves and advise them on the career path that most accurately fits them. And additionally function a complementary tool for career guide and counselors. during this analysis we've got studied career steering, designed a purposeful internet application and enforced it with some prosperous check results.

\section{REFERENCES}

[1]. Alhassan, J. K. (2013). Course Material On Expert Systems,Unpublished.

[2]. Atch. T., \& Bowers.J (2005). The ASCA National Mode: Afome Work For School Counseling Programs.

[3]. Bukoye, R.O. (2006). Career Guidance For Basic And Secondary School Education (2nd ED.). 
[4]. Cascading Style Sheets. In Wikipedia (January,2014) Retrieved From Http://En.Wikipedia.Org/Wiki/CSS_Style_Shee ts.

[5]. Dawn, R. M. (2012). "What Is Career Guidance" Retrieved From Http://Careerplanning.About.Com/Od/Careerc hoicechan /F/Career-Guidance.Htm. 6Design. In Wikipedia(January,2014) Retrieved From Http://En.Wikipedia.Org/Wiki/Design.

[6]. Gladding, S.T. (2004). Counseling: A Comprehensive Profession (5th Ed.). Upper Saddle River, NJ: Merril/Prentice Hall. O 6-7.

[7]. Glen, S. Notebook On Ethics, Legal Issues, And Standards For Counselors.

[8]. Guidance \&Counseling: Defining Guidance And Counseling And The Difference Between Them. (2009) Retrieved From Http://Www.Tvtc.Gov.Sa/English/Trainingunit s/Vocationalinsti tutes/TVTS/Trainees/Pages/Directionguidance. Aspx.

[9]. Hooley, T. (2012). "How The Internet Changed Career: Framing The Relationship Between Career Development And Online Technologies". Journal Of The National Institute For Career Education And Counseling (NICEC) 29: 3

[10]. Hooley, T., Watts, A. G., Sultana, R. G., \&Neary, S. (2013). "The 'Blueprint' Framework For Career Management Skills: A Critical Exploration". British Journal Of Guidance \&Counseling 41 (2): 117.

[11]. Hypertext Markup Language (HTML) (2014, March) Retrieved From Http://Www.Mediahex.Com/Hypertext_Marku p_Language_.

[12]. Information Systems. N.D. In Wikipedia (2014, January)Retrieved From Http://En.Wikipedia.Org/Wiki/ Information_Systems_(Discipline).
[13]. Information Systems. In Wikipedia (2014,January)Retrieved From Http://En.Wikipedia.Org/Wiki/Information_Sy stems.

[14]. Introduction To System Analysis And Design. (2014, January)Retrieved Form Http://Zolotarev.Fd.Cvut.Cz/Sni/Ct?Act=Show, File,9725.

[15]. Julia, F. (2014, January) The History Of Career Guidance Retrieved On January 23, 2014 From Http://Www.Ehow.Com/Info_8172663_Histor y-CareerGuidance.Html.

\section{Cite this article as :}

Harsh Mishra, Jatin Makad, Nikhil Pathak, Dr. Gaurav Soni, "Cloud Based Career Guidance System ", International Journal of Scientific Research in Computer Science, Engineering and Information Technology (IJSRCSEIT), ISSN : 2456-3307, Volume 7, Issue 2, pp.640-649, March-April-2021. Available at doi : https://doi.org/10.32628/CSEIT2172117 Journal URL : https://ijsrcseit.com/CSEIT2172117 